Mikrochim. Acta $118,75-84$ (1995)

\title{
Evaluation of the Analytical Performance of Inductively Coupled Plasma Mass Spectrometry for the Simultaneous Determination of Major and Minor Elements in Basic Slags
}

\author{
Aurora G. Coedo* and Teresa Dorado \\ Centro Nacional de Investigaciones Metalúrgicas (C.S.I.C.), Gregorio del Amo 8, \\ E-28040 Madrid, Spain
}

\begin{abstract}
The application of inductively coupled plasma mass spectrometry to the analysis of basic slags has been studied. A conventional dissolution-fusion procedure and a microwave digestion system were used for sample dissolution. Suitable selection of the analyte isotopes and the use of appropriate instrument settings and of internal standardization makes it possible to determine the major and minor elements in the same test sample dilution. Use of the omnirange device and low-abundance isotopes for the determination of the major elements is evaluated. The influence of the attack reagents is tested and the interferences caused by polyatomic ions are studied and corrected by applying elementary mathematical equations. For the major and minor elements considered, precision was found to be better than 1\% (RSD). Results are presented for three basic slag reference materials and the agreement between the certified and found values shows the capacity of the method accurately to determine elemental concentrations in basic slags.
\end{abstract}

Key words: inductively coupled plasma mass spectrometry, basic slags, isobaric and polyatomic interferences, microwave digestion procedure, simultaneous major and minor elements analysis.

The complex nature of slags and the wide variation of their composition makes a complete traditional analysis rather lengthy and difficult $[1,2]$. In addition to those considered as main constituents: $\mathrm{Ca}, \mathrm{Si}, \mathrm{P}, \mathrm{Mg}, \mathrm{Al}, \mathrm{Mn}$ and $\mathrm{Fe}$, slags usually contain small quantities of most of the elements in the metallurgical products with which the slags were in contact during the manufacturing process, as well as some

* To whom correspondence should be addressed 
of the elements in the fuels, ores and fluxes. Thus in the case of slags formed in the manufacture of alloy steels, Cr, V, Ti, Ni, etc may be expected. The complete analysis of a slag makes it necessary to determine the major, as well as the minor constituents. The history of special slags often gives a clue as to their approximate composition.

The focus of ICP-MS has so far been directed towards trace analysis [3-6]. However, a much more complete elemental profile could be obtained if elements at major concentrations were measured in the same sample [7], which is why the role of ICP-MS in atomic spectroscopy laboratories is changing to reflect new improvements and capabilities of ICP-MS instrumentation.

In this study the analytical performance of ICP-MS for the simultaneous complete analysis of basic slags was evaluated. Tests were performed either by using the so-called omni-range device [8] (a rod-offset-voltage that controls analyte transmission efficiency on a specific mass) and by selecting low-abundance isotopes for the analysis of major constituents.

Omni-range is made possible by maintaining the quadrupole under constant computer control. As a result of this computer - quadrupole interaction, high signals from analytes at $\mu \mathrm{g} \mathrm{g}^{-1}$ concentrations, which would otherwise saturate the detector, can be selectively filtered and measured in the same spectrum in which trace $\left(\mathrm{ng} \mathrm{g}^{-1}\right)$ level analytes are measured.

Apart from the considerable time and effort required for the conventional complete decomposition of basic slags, requiring an acid attack as a first step followed by an alkaline fusion of the insoluble residue, there is always concern about the presence of high levels of dissolved solids. As is known, for ICP-MS analysis the levels of dissolved solids should ideally be low (typically below $1 \mathrm{~g} \mathrm{l}^{-1}$ ) for optimum analytical performance [9]. To reduce the dissolved solids content, as well as the time consumed in the dissolution step and the risk of contamination during the sample manipulation process, a microwave digestion procedure was applied. This system provides one-step acid decomposition of the samples, under high pressure and temperature.

Although the basic isobaric and background spectral interferences in ICP-MS are well documented [10-12], the influences of the attack reagents employed in the fusion and in the MW digestion procedures were tested. Polyatomic ion interferences were also evaluated and corrected by applying elemental mathematical equations. Accuracy was evaluated by analysing three reference materials as representative of basic slags.

\section{Experimental}

Instrumentation

A Perkin-Elmer Sciex Elan 500 ICP-Mass Spectrometer with an Elan 5000 Computer system was used. Operating conditions and instrumental parameter used are described in Table 1. An MLS 1200 (Milestone) microwave oven and HPV-80 vessels (maximum pressure 150 bar) were employed.

\section{Reagents and Standards}

Deionized water (18 M $\Omega$ ) obtained from a Millipore Milli-Q system was used. The reagents used for sample dissolution were all Merck Suprapur materials. Merck spectroscopic-grade single-element 
Table 1. ICP-MS equipment and conditions used

\begin{tabular}{ll}
\hline Nebulizer & ryton crossflow \\
Interface cones & Pt sampler and skimmer \\
RF Power & $1200 \mathrm{~W}$ \\
Plasma Ar flow & $12.01 \mathrm{~min}-1$ \\
Auxiliary Ar flow & $0.901 \mathrm{~min}-1$ \\
Nebulizer Ar flow & $1.201 \mathrm{~min}-1$ \\
Sample flow & $0.901 \mathrm{~min}-1$ \\
Ion optics settings & standard \\
Dwell time & $30 \mathrm{~ms}$ \\
No. of sweeps & 30 \\
Number of replicates & 3 \\
Data acquisition & multichannel analysis, \\
& one point per mass \\
Resolution & $0.6 \mathrm{amu}$ \\
Estimated time per sample & $52 \mathrm{~s}$ \\
\hline
\end{tabular}

solutions at concentrations of $1000 \mu \mathrm{g} \mathrm{m} \mathrm{m}^{-1}$ were employed for calibration. Three basic slags (Reference Materials: British Chemical Standards Nos. 174/2, 381 and 382) were analysed.

\section{Sample Dissolution Procedures}

Glassware was soaked in 5\% v/v $\mathrm{HNO}_{3}$ for $2-3$ days. Solutions were stored in polypropylene vessels. Samples were dissolved according to two different procedures: hydrochloric acid dissolution followed by fusion of the residue with lithium tetraborate, and microwave digestion with hydrochloric and hydrofluoric acids.

Conventional digestion procedure. Approximately $0.2 \mathrm{~g}$ of finely powdered slag, weighed to the nearest $1 \mathrm{mg}$, were reacted with $50 \mathrm{ml}$ of $\mathrm{HCl}(37 \%)$, diluted $1+1$. After complete reaction the insoluble residue was filtered, transferred to a platinum crucible, ignited at about $800^{\circ} \mathrm{C}$ and fused with $1.00 \mathrm{~g}$ of lithium tetraborate $\left(\mathrm{Li}_{2} \mathrm{~B}_{4} \mathrm{O}_{7}\right)$ at about $1200^{\circ} \mathrm{C}$, until a clear melt was obtained. The solidified melt was added to the main acid solution. After cooling, the solution obtained was quantitatively transferred to a $200-\mathrm{ml}$ flask and made up to volume with water.

Microwave digestion system. Approximately $0.1 \mathrm{~g}$ of finely powdered slag, weighed to the nearest $1 \mathrm{mg}$, were introduced into an HPV-80 vessel and reacted with $10 \mathrm{ml}$ of $\mathrm{HCl}(37 \%)$ diluted $1+1$, and $0.5 \mathrm{ml}$ of $\mathrm{HF}$ ( $40 \%$ ). The vessel was inserted on a carousel (the heating program was developed for the simultaneous use of three vessels) and the microwave heating program in Fig. 1 was applied. After cooling, $5 \mathrm{ml}$ of $4 \%$ aqueous boric acid solution $\left(\mathrm{H}_{3} \mathrm{BO}_{3}\right)$ were added and volume was made up to $100 \mathrm{ml}$ with water. In order to avoid strong heating of the Teflon vessels, the program was interrupted by a 1-min cooling phase.

The choice of acids for dissolution is an important step for ICP-MS applications. Nitric acid matrices are generally regarded as being the best acid medium for ICP-MS analysis, since the constituent elements are already present in air entrained by the plasma. But with $\mathrm{HNO}_{3}$ (used in different proportions and combined with other reagents), it was not possible to dissolve completely the tested slag samples. With $\mathrm{HCl}$ and $\mathrm{HF}$ in the proportions described above, samples were dissolved quantitatively.

Blank solutions. Blank solutions containing the same quantities of reagents employed in the sample dissolution procedures were prepared. 


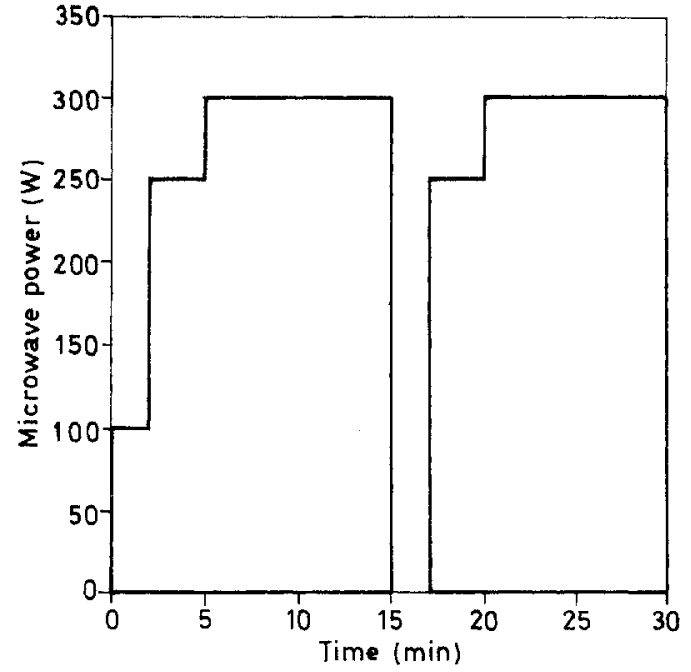

Fig. 1. Microwave digestion program

Table 2. Multielement calibration solutions for quantitative analysis. $100 \mathrm{ml}$ of solution, containing $10 \mathrm{ml}$ of the blank solution, $200 \mu \mathrm{g}$ of Sc and $20 \mu \mathrm{g}$ of Rh (as internal standards) and the following contents of test elements

\begin{tabular}{llr}
\hline Standard & Elements & Content \\
\hline 0 & none & \\
1 & $\mathrm{Fe}, \mathrm{Ca}$ & $500 \mu \mathrm{g}$ \\
& $\mathrm{Mg}, \mathrm{Al}, \mathrm{Mn}, \mathrm{Si}, \mathrm{P}$ & $100 \mu \mathrm{g}$ \\
& $\mathrm{Ti}, \mathrm{Cr}, \mathrm{V}, \mathrm{Ni}, \mathrm{Zn}, \mathrm{Cu}$ & $5 \mu \mathrm{g}$ \\
2 & $\mathrm{Fe}, \mathrm{Ca}$ & $1.0 \mathrm{mg}$ \\
& $\mathrm{Mg}, \mathrm{Al}, \mathrm{Mn}, \mathrm{Si}, \mathrm{P}$ & $200 \mu \mathrm{g}$ \\
& $\mathrm{Ti}, \mathrm{Cr}, \mathrm{V}, \mathrm{Ni}, \mathrm{Zn}, \mathrm{Cu}$ & $20 \mu \mathrm{g}$ \\
3 & $\mathrm{Fe}, \mathrm{Ca}$ & $2.5 \mathrm{mg}$ \\
& $\mathrm{Mg}, \mathrm{Al}, \mathrm{Mn}, \mathrm{Si}, \mathrm{P}$ & $500 \mu \mathrm{g}$ \\
& $\mathrm{Ti}, \mathrm{Cr}, \mathrm{V}, \mathrm{Ni}, \mathrm{Zn}, \mathrm{Cu}$ & $50 \mu \mathrm{g}$ \\
\hline
\end{tabular}

Test solutions. Samples and blank solutions for ICP-MS measurements were prepared by adding $20 \mu \mathrm{g}\left(200 \mu \mathrm{g} 1^{-1}\right)$ of $\mathrm{Rh}$ and $200 \mu \mathrm{g}\left(2 \mu \mathrm{g} \mathrm{1^{-1 }}\right)$ of Sc to $10 \mathrm{ml}$ of the original solutions and diluting to $100 \mathrm{ml}$ with $0.5 \% \mathrm{v} / \mathrm{v} \mathrm{HNO}_{3}$.

Calibration curves. Four calibration solutions were prepared as shown in Table 2. These were prepared from commercial $1.000 \mathrm{~g}^{-1}$ solutions.

\section{Results and Discussion}

\section{Major Elements}

The major elements considered were $\mathrm{Ca}, \mathrm{Fe}, \mathrm{Al}, \mathrm{Mg}, \mathrm{Mn}, \mathrm{Si}$ and $\mathrm{P}$. At the employed dilution factor of $10000(0.01 \mathrm{~g}$ in $100 \mathrm{ml})$ the basic slags produced solutions containing these main elements in the ranges of concentrations of the prepared calibration solutions. Measurements were performed by two different systems: use of the electronic filter of the ion signal at selected points in the mass 
spectrum (omni-range system) and use of low abundance isotopes. With the omnirange system a rod-offset-voltage is applied to the RF-only quadrupole located in front of the main quadrupole that controls analyte transmission efficiency on a specific mass. The omni-range has the effect of selectively reducing the sensitivity at specific masses within a single analytical measurement. Selecting a low-abundance isotope, if possible, can also be useful for major elements determination.

Tests were conducted to evaluate the omni-range setting (the offset voltage to the quadrupole mass spectrometer). The effect of omni-range depends on the isotope mass values, and for high-mass isotopes the influence is less than for lowmass isotopes. The masses of the evaluated elements were of the same magnitude, ranging from ${ }^{27} \mathrm{Al}$ to ${ }^{55} \mathrm{Fe}$, and consequently the omni-range setting influenced the responses in a very similar way, reducing the sensitivities at the specific masses selected in the same order of magnitude, as shown in Fig. 2. The precision (RSD) obtained with omni-range values from 0 to 2.5 was always better than $1 \%$. For omni-range settings up to 2.5 the RSD values increased above $2 \%$.

Three of the considered elements $\mathrm{P}, \mathrm{Al}$ and $\mathrm{Mn}$ are monoisotopic and the omni-range values employed were 0 for ${ }^{31} \mathrm{P}$, due to the low signal/noise ratio $(\mathrm{NOH}$ species interference) and 2.5 for ${ }^{27} \mathrm{Al}$ and ${ }^{55} \mathrm{Mn}$. In this way, according to Fig. 2, the sensitivities of ${ }^{27} \mathrm{Al}$ and ${ }^{55} \mathrm{Mn}$ were reduced by one hundred times while retaining maximum sensitivity for ${ }^{31} \mathrm{P}$.

All the other major elements present have more than one natural isotope. The isotopes for quantitative measurement were selected in terms of the interferences and the precision.

Table 3 shows the intensities and the RSD values for the different isotopes of $\mathrm{Ca}, \mathrm{Fe}, \mathrm{Si}$ and $\mathrm{Mg}$. Some of these isotopes cannot be used for quantitative measurements because of polyatomic ion interferences. A study of interferences was carried out by measuring the contribution from solutions containing $10 \mu \mathrm{g} \mathrm{ml}^{-1}$ of each element to the peaks of the other measured elements. Ca produces interferences in some $\mathrm{Fe}$ isotopes. A contribution from ${ }^{40} \mathrm{Ca}^{15} \mathrm{O}$ to the peak of ${ }^{56} \mathrm{Fe}$ was found; moreover, this $\mathrm{Fe}$ isotope presented a high background (from ${ }^{40} \mathrm{Ar}^{16} \mathrm{O}^{+}$),

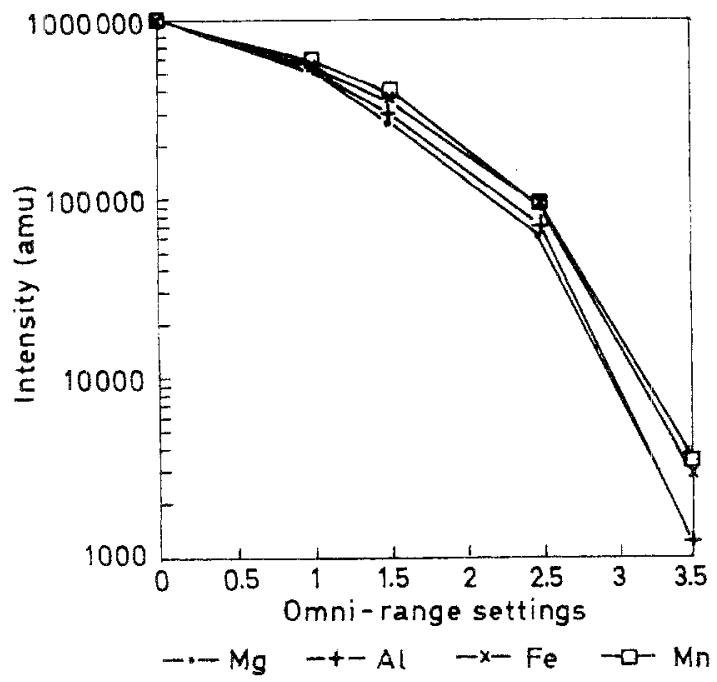

Fig. 2. Effect of omni-range settings on ${ }^{24} \mathrm{Mg},{ }^{27} \mathrm{Al},{ }^{54} \mathrm{Fe}$ and ${ }^{55} \mathrm{Mn}$ ion intensities 
Table 3. Intensities and RSD values for $25 \mu \mathrm{g} \mathrm{ml}^{-1}$ of $\mathrm{Fe}, \mathrm{Ca}$ and $5 \mu \mathrm{g} \mathrm{ml}^{-1}$ of Si and $\mathrm{Mg}$

\begin{tabular}{llll}
\hline Isotope & Omni-range & Counts s $^{-1}\left(\times 10^{3}\right)$ & RSD \\
\hline${ }^{56} \mathrm{Fe}(91.66 \%)$ & 3 & 1100 & 3.0 \\
${ }^{54} \mathrm{Fe}(5.82 \%)$ & 1.5 & 1000 & 0.75 \\
${ }^{57} \mathrm{Fe}(2.19 \%)$ & 0 & 1100 & 0.70 \\
${ }^{44} \mathrm{Ca}(2.06 \%)$ & 1.5 & 500 & 0.55 \\
${ }^{42} \mathrm{Ca}(0.64 \%)$ & 0 & 500 & 0.62 \\
${ }^{28} \mathrm{Si}(92.21 \%)$ & 1.5 & 800 & 0.90 \\
${ }^{29} \mathrm{Si}(4.7 \%)$ & 0 & 200 & 0.87 \\
${ }^{24} \mathrm{Mg}(78.7 \%)$ & 1.5 & 1300 & 0.72 \\
${ }^{25} \mathrm{Mg}(10.13 \%)$ & 0 & 800 & 0.50 \\
${ }^{26} \mathrm{Mg}(11.17 \%)$ & 0 & 880 & 0.48 \\
\hline
\end{tabular}

The most abundant isotope of $\mathrm{Ca}\left({ }^{40} \mathrm{Ca}\right)$ was not considered because of interference by ${ }^{40} \mathrm{Ar}$.

producing a off-scale signal and making it necessary to use a high omni-range setting. An interference was also found from ${ }^{40} \mathrm{Ca}^{16} \mathrm{OH}^{+}$to the peak of ${ }^{57} \mathrm{Fe}$ (the measured Fe equivalent concentration for $\mathrm{Ca}$ at $10 \mu \mathrm{g} \mathrm{ml}^{-1}$ was $0.2 \mu \mathrm{g} \mathrm{ml}^{-1}$ ). Elsewhere ${ }^{54} \mathrm{Fe}$ had a spectral overlap with ${ }^{54} \mathrm{Cr}$, but this interference could be corrected by applying the following equation:

$$
\begin{aligned}
I\left({ }^{54} \mathrm{Fe}\right) & =I(54)-\left[I(53) \times \frac{a\left({ }^{54} \mathrm{Cr}\right)}{a\left({ }^{53} \mathrm{Cr}\right)}\right] \\
& =I(54)-[I(53) \times 0.2492]
\end{aligned}
$$

where $I=$ intensity at the specified mass and $a=$ abundance of the isotope.

This correction was made considering the ${ }^{53} \mathrm{Cr}$ isotope intensity (abundance $=$ 9.54\%). As the Cr content in these materials is generally low and the two considered $\mathrm{Cr}$ isotopes present a poor abundance, the correction factor is not significant.

With regard to $\mathrm{Ca}$ determination, an interference was found in ${ }^{44} \mathrm{Ca}$, caused by ${ }^{28} \mathrm{Si}^{16} \mathrm{O}$ (the Ca equivalent concentration for $10 \mu \mathrm{g} \mathrm{ml}^{-1}$ of Si was $0.4 \mu \mathrm{g} \mathrm{ml}^{-1}$ ). No other significant polyatomic ion interferences were detected for the major elements determination, and the apparent enhancements or suppressions were within the measurement precision range foreseen. On the basis of these studies the isotopes selected were ${ }^{54} \mathrm{Fe},{ }^{42} \mathrm{Ca},{ }^{28} \mathrm{Si}\left({ }^{29} \mathrm{Si}\right.$ gives poor sensitivity) and ${ }^{26} \mathrm{Mg}$ (this $\mathrm{Mg}$ isotope gives good sensitivity and the best precision).

\section{Minor Elements}

The minor elements considered were $\mathrm{Ti}, \mathrm{Cr}, \mathrm{V}, \mathrm{Ni}, \mathrm{Zn}$ and $\mathrm{Cu}$. This group was selected from a semi-quantitative analysis of the three CRM samples, which showed the presence of such elements. A study of matrix and interelemental interferences was made. This study proved the interferences from ${ }^{58} \mathrm{Fe}$ (isotopic abundance $0.33 \%)$ and from ${ }^{42} \mathrm{Ca}^{16} \mathrm{O}$ on the most abundant $\mathrm{Ni}$ isotope $\left({ }^{58} \mathrm{Ni}, 67.84 \%\right)$. $\mathrm{As} \mathrm{Fe}$ and $\mathrm{Ca}$ are major elements in basic slags, it was better to use a low-abundant 
isotope for $\mathrm{Ni}$ determination $\left({ }^{60} \mathrm{Ni}, 26.23 \%\right.$ ) than to introduce a correction factor to compensate for these interferences. However, for Ti determination it was better to correct the isobaric interference produced by ${ }^{48} \mathrm{Ca}$ (isotopic abundance of $0.18 \%$ ) on the most abundant $\mathrm{Ti}$ isotope $\left({ }^{48} \mathrm{Ti}, 73.94 \%\right)$, because of the poor sensitivity of the interference-free Ti isotopes.

This correction can be calculated by:

$$
\begin{aligned}
I\left({ }^{48} \mathrm{Ti}\right) & =I(48)-\left[I(43) \times \frac{a\left({ }^{48} \mathrm{Ca}\right)}{a\left({ }^{43} \mathrm{Ca}\right)}\right] \\
& =I(48)-[I(43) \times 1.24138] .
\end{aligned}
$$

For $\mathrm{Zn}$ determination the same precision was obtained using the interferencefree ${ }^{66} \mathrm{Zn}$ isotope (isotopic abundance $27.81 \%$ ) as with the most abundant one $\left({ }^{64} \mathrm{Zn}, 48.89 \%\right)$, after being corrected for Ni interference according to the following equation:

$$
\begin{aligned}
I\left({ }^{64} \mathrm{Zn}\right) & =I(64)-\left[I(61) \times \frac{a\left({ }^{64} \mathrm{Ni}\right)}{a\left({ }^{6} \mathrm{Ni}\right)}\right] \\
& =I(64)-[I(61) \times 0.9075] .
\end{aligned}
$$

Determination of the other elements considered posed no particular problems in this context, and their most abundant isotopes could be used.

All these correction factors were added to the software of the instrument and were applied automatically for quantitative analysis.

\section{Background Correction}

A study of the background spectral features was made in order to recognize spectral interferences from the reagents used in the sample dissolution procedures. The two systems used introduced $\mathrm{HCl}$ in the solutions and consequently the problems associated with a chloride matrix appeared. Vanadium was the most affected of the considered analytes. A chloride-containing matrix results in the formation of ${ }^{35} \mathrm{Cl}^{16} \mathrm{O}$ and ${ }^{37} \mathrm{Cl}^{14} \mathrm{~N}$, which interfere with ${ }^{51} \mathrm{~V}$ (the only isotope for $\mathrm{V}$ ). This interference produced a high background, increasing the background equivalent concentration (BEC) value, but it was controlled by using calibration solutions containing the same proportion of reagents. No more spectral interference problems were observed with the analyte masses used.

ICP-MS measurements were carried out according to the operational parameters listed in Table 1. With a data acquisition group of 15 elements (one mass per element, 13 analytes and 2 internal standards), a replicate time of $900 \mathrm{~ms}$ (dwelltime $=30 \mathrm{~ms} ; 30$ sweeps) and 3 replicates, each spectrum was accumulated in approximately $52 \mathrm{~s}$. Blank and calibration solutions containing the same reagents as the test samples were used in every case. To avoid memory effects, $0.5 \%(\mathrm{v} / \mathrm{v})$ $\mathrm{HNO}_{3}$ was used as rinsing liquid after measurement of each sample.

It was found that the best results were obtained when the internal standard had omni-range values close to those of its standard group's omni-range values. Thus, 
Sc (at $2 \mu \mathrm{g} \mathrm{ml}^{-1}$ with omni-range setting $=1.5$ ), and $\mathrm{Rh}$ (at $200 \mathrm{ng} \mathrm{ml}^{-1}$ with omnirange setting $=1$ ) were used as internal standards for major and minor elements, respectively.

The short-term stability was evaluated from the intensities obtained by measuring ten times the multielement calibration solution containing $200 \mathrm{ng} \mathrm{ml}^{-1}$ of the minor and trace elements. The relative standard deviation (RSD) of the signals was, on average, below $2.5 \%$. By using $\mathrm{Rh}$ (present in the solutions at $200 \mathrm{ng} \mathrm{m}^{-1}$ ) as internal standard, the average RSD was similar to the value obtained above. However the long-term stability, evaluated from the intensities measured over a 30 -min period, gave RSD values up to $5 \%$, and improved significantly when an internal standard was used, achieving RSD values very close to those obtained on the short-term stability test.

Due to the high saline concentration, the background and the net intensity peak values obtained from the lithium tetraborate fusion procedure were generally lower than those provided by the microwave digestion system. Nevertheless the background equivalent concentration values and the detection limits (expressed as for test solutions containing the same sample proportion) achieved with both systems were quite similar.

All the tests were carried out in solutions diluted $10^{4}$ times, and at this dilution factor the level of dissolved solids was below $0.05 \mathrm{~g} / 100 \mathrm{ml}$, even when the lithium tetraborate fusion procedure was employed, and the variations observed in the results obtained from these two systems of sample dissolution were within the measurement precision. The calibration curves gave correlation coefficients between 0.9993 and 1.0000. Nevertheless, the stability of the solutions, the greater speed, the low level of manipulation and the lower level of saline concentration provided by the microwave digestion procedure, make this system more suitable.

Table 4 gives the isotope masses used for determination, together with the correlation coefficients for the major elements and the background equivalent concentrations and the detection limits (based on $3 \sigma$ values for the blank solution), for the minor elements, all from microwave dissolutions. Concentration values and uncertainty limits for the analyses of the certified elements in the three tested standard reference materials are reported in Table 5. Each value is the average of four measurements and each measurement was made on a different sample. The results obtained for both major and minor elements are in good agreement with the certified values.

\section{Conclusions}

The results show the capacity of the inductively coupled plasma mass spectrometry technique for performing accurate and precise determination of major and minor elements in basic slags. All the elements can be determined from the same diluted solution by using low-abundance isotopes and the omni-range device for major element measurements, and with an internal standard having an omni-range value close to those of the elements included in the corresponding standard group. The use of a microwave digestion system for sample dissolution reduces the analysis time considerably and produces stable solutions with low solids concentration, making it possible to use sample dilution factors lower than $10^{4}$ when trace 
Table 4. Isotopes used to determine analytical concentrations. Correlation coefficients for major elements calibrations, with reagent blank equivalent concentrations (BEC) and detection limits (DL) for minor elements

\begin{tabular}{|c|c|c|}
\hline $\begin{array}{l}\text { Isotope } \\
\text { (abundance) }\end{array}$ & & $\begin{array}{l}\text { Correlation } \\
\text { coefficient }\end{array}$ \\
\hline${ }^{54} \mathrm{Fe}(5.82 \%)$ & & 1.0000 \\
\hline${ }^{44} \mathrm{Ca}(2.06 \%)$ & & 0.9998 \\
\hline${ }^{28} \mathrm{Si}(92.21 \%)$ & & 0.9994 \\
\hline${ }^{26} \mathrm{Mg}(11.17 \%)$ & & 1.0000 \\
\hline${ }^{27} \mathrm{Al}\left(100^{\circ} \%\right)$ & & 0.9999 \\
\hline${ }^{55} \mathrm{Mn}(100 \%)$ & & 1.0000 \\
\hline${ }^{31} \mathrm{P}(100 \%)$ & & 0.9991 \\
\hline $\begin{array}{l}\text { Isotope } \\
\text { (abundance) }\end{array}$ & $\begin{array}{l}\mathrm{BEC} \\
\left(\mathrm{ng} \mathrm{ml} \mathrm{l}^{-1}\right)\end{array}$ & $\begin{array}{l}\mathrm{DL}^{\mathrm{a}} \\
\left(\mu \mathrm{g} \mathrm{g}^{-1}\right)\end{array}$ \\
\hline${ }^{52} \mathrm{Cr}(83.76 \%)$ & 2.1 & 1.8 \\
\hline${ }^{60} \mathrm{Ni}(26.23 \%)$ & 0.50 & 1.5 \\
\hline${ }^{48} \mathrm{Ti}(73.94 \%)$ & 1.1 & 0.95 \\
\hline${ }^{66} \mathrm{Zn}(27.81 \%)$ & 15.0 & 7.9 \\
\hline${ }^{63} \mathrm{Cu}(69.09 \%)$ & 0.35 & 1.0 \\
\hline${ }^{51} \mathrm{~V}(99.76 \%)$ & 10.0 & 4.5 \\
\hline
\end{tabular}

a $\mathrm{DL}=$ concentration which gives a signal equal to three times the SD of the blank, expressed as for test solutions containing $0.1 \mathrm{mg} \mathrm{ml}^{-1}$ of sample.

Table 5. Composition $(\% \mathrm{~m} / \mathrm{m})$ of standard reference materials

\begin{tabular}{|c|c|c|c|c|c|c|}
\hline & \multicolumn{2}{|c|}{ B.C.S. $174 / 2$} & \multicolumn{2}{|c|}{ B.C.S. 381} & \multicolumn{2}{|c|}{ B.C.S. 382} \\
\hline & Cert. & Found $^{a}$ & Cert. & Found $^{2}$ & Cert. & Found $^{\mathrm{a}}$ \\
\hline Total Fe & 15.9 & $15.78 \pm 0.25$ & 13.3 & $13.07 \pm 0.22$ & 11.6 & $11.73 \pm 0.24$ \\
\hline $\mathrm{CaO}$ & 43.2 & $43.00 \pm 0.37$ & 49.0 & $48.75 \pm 0.30$ & 33.0 & $33.35 \pm 0.30$ \\
\hline $\mathrm{SiO}_{2}$ & 11.2 & $11.08 \pm 0.16$ & 8.78 & $8.90 \pm 0.15$ & 19.5 & $19.65 \pm 0.18$ \\
\hline $\mathrm{P}_{2} \mathrm{O}_{5}$ & 11.9 & $12.02 \pm 0.20$ & 15.7 & $15.5 \pm 0.22$ & 1.23 & $1.15 \pm 0.10$ \\
\hline $\mathrm{MgO}$ & 4.63 & $4.58 \pm 0.08$ & 1.03 & $0.95 \pm 0.08$ & 10.7 & $11.00 \pm 0.15$ \\
\hline $\mathrm{MnO}$ & 3.80 & $3.75 \pm 0.08$ & 3.16 & $3.20 \pm 0.05$ & 9.20 & $9.10 \pm 0.12$ \\
\hline $\mathrm{Al}_{2} \mathrm{O}_{3}$ & 0.77 & $0.75 \pm 0.03$ & 0.67 & $0.70 \pm 0.04$ & 7.51 & $7.62 \pm 0.10$ \\
\hline $\mathrm{V}_{2} \mathrm{O}_{5}$ & 0.96 & $1.00 \pm 0.12$ & 0.94 & $0.92 \pm 0.10$ & 0.15 & $0.13 \pm 0.07$ \\
\hline $\mathrm{TiO}_{2}$ & 0.53 & $0.50 \pm 0.02$ & 0.35 & $0.33 \pm 0.01$ & 0.50 & $0.50 \pm 0.02$ \\
\hline $\mathrm{Cr}_{2} \mathrm{O}_{3}$ & $(0.22)$ & $0.22 \pm 0.01$ & 0.33 & $0.33 \pm 0.01$ & 1.20 & $1.25 \pm 0.02$ \\
\hline
\end{tabular}

$\mathrm{n}=4$.

elements at very low levels must be determined: Isobaric interferences can be controlled by applying calculated correction factors. The reagent's background influence is offset by matching calibration solutions. As some elements are present at high concentrations, it is essential to pay particular attention to memory effects and to nebulize dilute nitric acid between samples. 
Acknowledgement. The assays concerning development of the microwave sample procedure form part of a research project financially supported by the European Community for Steel and Carbon (ECSC), No. 7210/GD/935.

\section{References}

[1] Standard Methods of Analysis of Iron, The United Steel Companies, Sheffield, 1961, p. 179.

[2] G. E. F. Lundell, J. I. Hoffman, M. S. Bright, Chemical Analysis of Iron and Steel, Wiley, New York, 1950, p. 590.

[3] I. Gustavsson, H. Larson, Progress of Analytical Chemistry in the Iron and Steel Industry, Commission of the European Communities, Eur 14133, Luxembourg, 1992, p. 193.

[4] M. B. Shabani, A. Masuda, Anal. Chim. Acta 1992, 261, 315.

[5] S. Itoh, F. Hirose, R. Hasegawa, Spectrochim. Acta B 1992, 47, 1241.

[6] K. Akatsuka, J. W. Mclaren, J. W. Lam, S. S. Berman, J. Anal. At. Spectrom. 1992, 7, 887.

[7] R. Alaimo, P. Censi, Atom. Spectrosc. 1992, 13, 113.

[8] E. R. Denoyer, Technical Summary, Perkin Elmer, Order No. TSMS-15.

[9] C. J. Amarasiriwardena, B. Gercken, M. D. Argentine, R. M. Barnes, J. Anal. At. Spectrom. $1990,5,457$.

[10] S. H. Tan, G. Horlick, Appl. Spectrosc. 1986, 40, 445.

[11] M. A. Vaughan, G. Horlick, Appl. Spectrosc. 1986, 40, 434.

[12] K. E. Jarvis, A. L. Gray, R. S. Houk, Handbook of Inductively Coupled Plasma Mass Spectrometry, Chapman and Hall, London, 1992.

Received August 2, 1994. Revision November 29, 1994. 